\title{
Processamento de cerâmicas reticuladas a partir de matérias-primas naturais
}

\section{(Processing of reticulated ceramics using natural raw material)}

\author{
F. R. Albuquerque 1 , S. J. G. Lima ${ }^{2}$, C. A. Paskocimas 3 , E. Longo ${ }^{4}$, A. G. Souza ${ }^{1}$, I. M. G. Santos \\ ${ }^{1} L T M-D Q-C C E N,{ }^{2} L S R-D E M-C T$, Universidade Federal da Paraíba \\ Cidade Universitária, Campus I, João Pessoa, PB 58050-900 \\ ${ }^{3}$ DEM-CT, Universidade Federal do Rio Grande do Norte \\ Campus Universitário, Natal, RN 59072-970 \\ ${ }^{4}$ LIEC-CMDMC, Instituto de Química, UNESP, R. Prof. Francisco Degni s/n, Araraquara, SP 14800-900 \\ ieda@quimica.ufpb.br
}

\begin{abstract}
Resumo
Foram produzidas cerâmicas porosas reticuladas a partir de uma matéria-prima natural (AF) empregada na produção de telhas e tijolos, misturando-a com caulim (AC). A matéria-prima AF é constituída basicamente de quartzo e feldspatos. O método empregado para confecção das peças cerâmicas foi o da impregnação em espuma polimérica. Foram otimizadas as viscosidades de barbotinas contendo $70 \% \mathrm{~m} / \mathrm{m}$, utilizando poliacrilato de sódio (PAA-Na) como defloculante. As suspensões com $70 \% \mathrm{~m} / \mathrm{m}$ de AF apresentaram viscosidade em torno de $600 \mathrm{mPa}$.s, reduzindo para $300 \mathrm{mPa}$.s após adição de $20 \% \mathrm{~m} / \mathrm{m}$ de AC. O teor de PAA-Na empregado para a fabricação das cerâmicas porosas foi 2,0\% m/m. A tixotropia e a pseudoplastia das barbotinas facilitaram a impregnação de espumas poliméricas com 5, 10 e 40 poros/cm. As cerâmicas reticuladas foram obtidas após sinterização a 1100 e $1200{ }^{\circ} \mathrm{C}$. Os difratogramas de raios X indicaram a dissolução do quartzo a $1200^{\circ} \mathrm{C}$, com uma peça apresentando basicamente mulita e fase vítrea. As cerâmicas reticuladas com porosidade 10 poros/cm apresentaram estrutura suficientemente rígida com resistência mecânica superior a 1,70 MPa e com constante de permeabilidade darciana na ordem de $3,58.10^{-9}( \pm 10,0 \%) \mathrm{m}^{2}$.

Palavras-chave: cerâmica reticulada, matérias-primas naturais, espuma polimérica.
\end{abstract}

\begin{abstract}
Porous reticulated ceramics were obtained using a natural raw material (AF) usually employed in the production of tiles and bricks, with kaolinite (AC) addition. The AF raw material is constituted of quartz and feldspar. Ceramic pieces were processed using the polymeric sponge impregnation. Viscosities of the slurries with $70 \%$ of solids (wt./wt.) were optimized using sodium polyacrilate (PAA-Na) as deffloculant. Suspensions without AC addition presented a viscosity of $600 \mathrm{mPa}$.s, decreasing to $300 \mathrm{mPa}$.s after addition of $20 \%$ (wt./wt.) AC. The optimized amount of PAA-Na was $2.0 \%$ (wt./wt.). Tixotropy and pseudoplasty of the slurries made the impregnation process easier. Polymeric sponges of 5, 10 and 40 pores/cm were used. Ceramic pieces were sintered at 1100 and $1200^{\circ} \mathrm{C}$. X-ray diffractograms indicated the quartz dissolution at $1200^{\circ} \mathrm{C}$, leading to a material composed of mullite and vitreous phase. Reticulated ceramics with a porosity of 10 pores/cm presented a rigid structure with mechanical strength higher than $1.70 \mathrm{MPa}$, with darcian permeability constant of about $3.58 \times 10^{-9}( \pm 10.0 \%) \mathrm{m}^{2}$.
\end{abstract}

Keywords: traditional ceramics, shaping, suspensions, clays, functional applications.

\section{INTRODUÇÃO}

As cerâmicas reticuladas são caracterizadas por terem espaços interconectados através de uma rede cerâmica [1] apresentando, portanto, uma reduzida densidade volumétrica. As propriedades físicas, químicas e mecânicas das cerâmicas reticuladas permitem empregá-las em vários ramos da indústria: na indústria metalúrgica as cerâmicas reticuladas são utilizadas para remoção de impurezas em metais fundidos [2]; no setor automobilístico atuam no controle de emissão de particulados em gases provenientes de motores a diesel [3]; também são usadas como suporte catalítico [4] na indústria petroquímica, na imobilização de biomassa para tratamento de águas residuais [5]; e recentemente têm sido usadas na área de biomateriais para implantes de reposição óssea [6].

Há dois métodos bem difundidos para a produção de cerâmicas reticuladas: o gelcasting [7] e o método de impregnação em espuma polimérica [8]. Neste trabalho utilizou-se o método de impregnação em espuma polimérica. 
Este processo pode ser resumido nas seguintes etapas: seleção da espuma polimérica com a porosidade desejada, preparação da suspensão cerâmica, imersão da espuma nesta suspensão, remoção do excesso de material impregnado, secagem e tratamento térmico para eliminação da espuma polimérica, e sinterização da peça cerâmica.

No método de impregnação em espuma polimérica, além do defloculante, utiliza-se aditivos para melhorar as propriedades reológicas das suspensões cerâmicas de modo a facilitar a impregnação na espuma polimérica. Estas substâncias são: (i) ligante - dá ao corpo de prova resistência mecânica após remoção do solvente e evita o colapso da peça após a pirólise da espuma; (ii) agente reológico - promove tixotropia e pseudoplastia facilitando a impregnação da espuma polimérica pela suspensão cerâmica; (iii) antiespumante - evita a formação de bolhas na suspensão cerâmica; (iv) agente aderente - promove a aderência entre a suspensão cerâmica e a espuma orgânica [9].

Em decorrência do material cerâmico usualmente empregado (cordierita, carbeto de silício, mulita, alumina) [9], a temperatura utilizada para a sinterização das peças cerâmicas é usualmente superior a $1200{ }^{\circ} \mathrm{C}$. A temperatura elevada, os custos com mão de obra e com a matéria-prima, além dos aditivos utilizados na preparação das suspensões cerâmicas, oneram a produção das cerâmicas porosas reticuladas.

Objetivando reduzir custos com a produção das cerâmicas reticuladas fez-se a opção de produzi-las com matérias-primas naturais, que apresentam baixo custo [10], utilizando caulinita, feldspato e quartzo, que são materiais bem conhecidos na indústria cerâmica tradicional. A caulinita promove tixotropia e pseudoplastia nas barbotinas, reduzindo os custos com aditivos reológicos; os feldspatos são fluxantes usados em cerâmicas brancas e vidrados de silicatos, reduzindo a temperatura de sinterização, e o quartzo é usado em cerâmica branca refratária e composições vítreas, atuando como "filler" [11].

Neste trabalho foram confeccionadas cerâmicas porosas reticuladas, utilizando uma matéria-prima empregada na fabricação de telhas e tijolos (AF), constituída basicamente por quartzo e feldspatos, como base. Tal matéria-prima é proveniente do município de Santa Rita, PB, Brasil. Complementarmente, foram verificados os efeitos da adição de caulim (AC), como também o efeito da temperatura de sinterização (1100 e $\left.1200{ }^{\circ} \mathrm{C}\right)$, nas propriedades das cerâmicas reticuladas.

\section{MATERIAIS E MÉTODOS}

\section{Caracterização das matérias-primas}

A matéria-prima base AF e a caulinita AC foram moídas a úmido em um moinho de bolas tipo periquito (CT-242 Servitech). Em seguida os materiais foram secos em ar e depois em estufa a $110{ }^{\circ} \mathrm{C}$. Posteriormente foram homogeneizados. Curvas de distribuição de tamanho de partícula foram obtidas em um equipamento Quantachrome Nova-2000.

A caracterização mineralógica das matérias-primas foi feita por difração de raios X (DRX), utilizando o equipamento D-5000 Siemens, com radiação $\mathrm{K}_{\alpha}(\mathrm{Cu})$.

A análise química quantitativa da matéria-prima base AF foi realizada por espectroscopia de absorção e emissão atômica (AAnalyst 100, Perkin Elmer). Para abertura da amostra, foi empregado o método de fusão com metaborato e dissolução em ácido nítrico [12].

Curvas termogravimétricas (TG) das amostras AF e AC e da espuma polimérica, utilizada na impregnação, foram determinadas em um equipamento TGA-50 Shimadzu, com uma razão de aquecimento de $10^{\circ} \mathrm{C} \cdot \mathrm{min}^{-1}$, e fluxo de ar atmosférico de $20 \mathrm{~mL} \cdot \mathrm{min}^{-1}$. Para obtenção das curvas térmicas diferenciais (DTA), foi utilizado um equipamento DTA-50 Shimadzu, com uma razão de aquecimento de 50 ${ }^{\circ} \mathrm{C} \cdot \mathrm{min}^{-1}$ para a AC [13], e $10{ }^{\circ} \mathrm{C} \cdot \mathrm{min}^{-1}$ para as amostras AF, com 0 a $20 \%$ de AC. Para o ensaio de DTA foi usada $\alpha$ alumina como padrão. As massas das amostras utilizadas nos experimentos foram de $\sim 20,0 \mathrm{mg}$.

\section{Caracterização das suspensões}

As viscosidades de suspensões contendo $70 \% \mathrm{~m} / \mathrm{m}$ de sólidos, compostas de AF com 0, 10 e 20\% de AC, foram otimizadas com o defloculante poliacrilato de sódio (PAANa). Utilizou-se um viscosímetro LV DV II - BrooKfield, com spindle 25. A viscosidade foi determinada em uma taxa de cisalhamento de $44 \mathrm{~s}^{-1}$ a $25^{\circ} \mathrm{C}$. As suspensões cerâmicas foram preparadas em recipiente hermético para evitar perda de umidade, deixando-as estabilizando por $10 \mathrm{~min}$.

\section{Obtenção e caracterização das cerâmicas porosas reticuladas}

Para a obtenção das cerâmicas porosas reticuladas, após otimização das suspensões, foram impregnadas 3 espumas poliméricas (5, 10 e 40 poros/cm - ppc), denominadas, respectivamente, $\mathrm{P}, \mathrm{M}$ e G. Após impregnação foi removido o excesso de barbotina com o uso de uma calandra com abertura de $\sim 30 \%$ da dimensão da espuma.

As peças impregnadas foram secas inicialmente à temperatura ambiente e em seguida $110{ }^{\circ} \mathrm{C}$. O tratamento térmico foi realizado em duas etapas: a primeira com razão de aquecimento de $2{ }^{\circ} \mathrm{C} \cdot \mathrm{min}^{-1}$ até $250{ }^{\circ} \mathrm{C}$, com patamar de 1 h, para a pirólise da espuma polimérica, evitando o colapso da estrutura cerâmica; a segunda etapa foi realizada com razão de aquecimento de $1{ }^{\circ} \mathrm{C} \cdot \mathrm{min}^{-1}$, com patamar de $2 \mathrm{~h}$, nas temperaturas de 1100 e $1200{ }^{\circ} \mathrm{C}$. Para verificação da estrutura porosa das cerâmicas reticuladas, foram obtidas fotografias em uma lupa Leica MZ12.

As espumas com 5 ppc (G) foram utilizadas para avaliação da porosidade aparente, massa específica e absorção de 
água após tratamento térmico, utilizando o método de Arquimedes. Os testes de resistência mecânica e os ensaios de permeabilidade foram realizados com as peças com porosidade 10 ppc. Para os ensaios de resistência mecânica as cerâmicas reticuladas foram capeadas com uma pasta de cimento, e para distribuir melhor a carga na superfície da peça cerâmica foi utilizada uma película de borracha. A velocidade de compressão foi de $1,36 \times 10^{-3} \mathrm{~m} \cdot \mathrm{min}^{-1}$. O equipamento utilizado foi um Versa-Tester $30 \mathrm{M}$.

Para a determinação das constantes de permeabilidade da cerâmica reticulada com 10 ppc, empregou-se a equação proposta por Reynolds e Forchheiner [14]. Para determinação das constantes darciana $\mathrm{k}_{1}$ e não-darciana $\mathrm{k}_{2}$ montou-se um sistema com um leito de $0,50 \mathrm{~m}$ de comprimento (L), apresentando um diâmetro de $1,76.10^{-2} \mathrm{~m}$ (Fig. 1).

$$
\frac{\Delta \mathrm{p}}{\mathrm{L}}=\frac{\mu}{\mathrm{k}_{1}} \mathrm{v}_{\mathrm{s}}+\frac{\rho}{\mathrm{k}_{2}} \mathrm{v}_{\mathrm{s}}^{2}
$$

onde $\mu\left(8,45.10^{-4}\right.$ Pa.s) e $\rho\left(997,4\right.$ kg.m $\left.{ }^{-3}\right)$ são a viscosidade e a densidade da água, na temperatura de $27^{\circ} \mathrm{C}$. Durante os ensaios foram determinadas as variações de pressão, $\Delta \mathrm{p}$, e as velocidades do fluido, $\mathrm{v}_{\mathrm{s}}$.

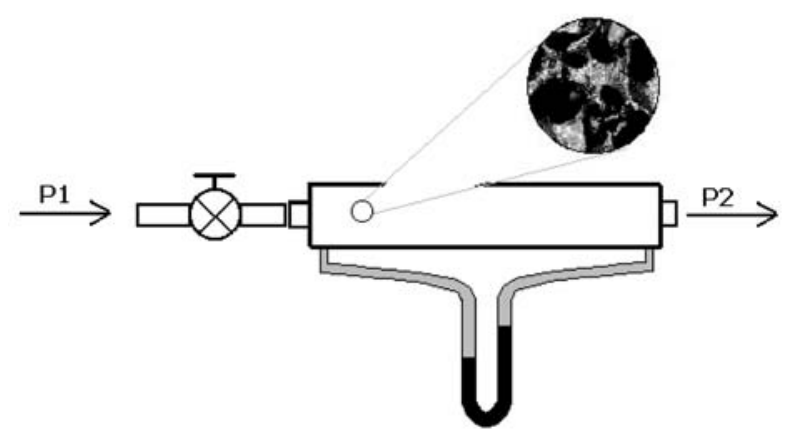

Figura 1: Sistema utilizado para determinação das constantes de permeabilidade darciana $\left(\mathrm{k}_{1}\right)$ e não darciana $\left(\mathrm{k}_{2}\right)$.

[Figure 1: System used to determine the permeability constants: Darcian $\left(k_{1}\right)$ and non-Darcian $\left(k_{2}\right)$.]

\section{RESULTADOS E DISCUSSÃO}

\section{Matérias-primas}

No difratograma de raios X da matéria-prima AF (Fig. 2a) pode-se verificar que esta é composta basicamente por feldspatos - albita $\left(\mathrm{NaAlSi}_{3} \mathrm{O}_{8}\right)$ e microclina $\left(\mathrm{KAlSi}_{3} \mathrm{O}_{8}\right)$, quartzo $\left(\mathrm{SiO}_{2}\right)$ e pirofilita $\left(\mathrm{Al}_{2} \mathrm{Si}_{4} \mathrm{O}_{10}(\mathrm{OH})_{2}\right)$. Na Fig. $2 \mathrm{~b}$ constata-se que o caulim AC é composto basicamente por caulinita, muscovita e quartzo.

Na Tabela I observa-se que a AF apresenta um teor de óxidos fundentes na ordem de 4,25\%, com 61,40\% de sílica, além de óxido de ferro. $\mathrm{O}$ processo de moagem foi realizado

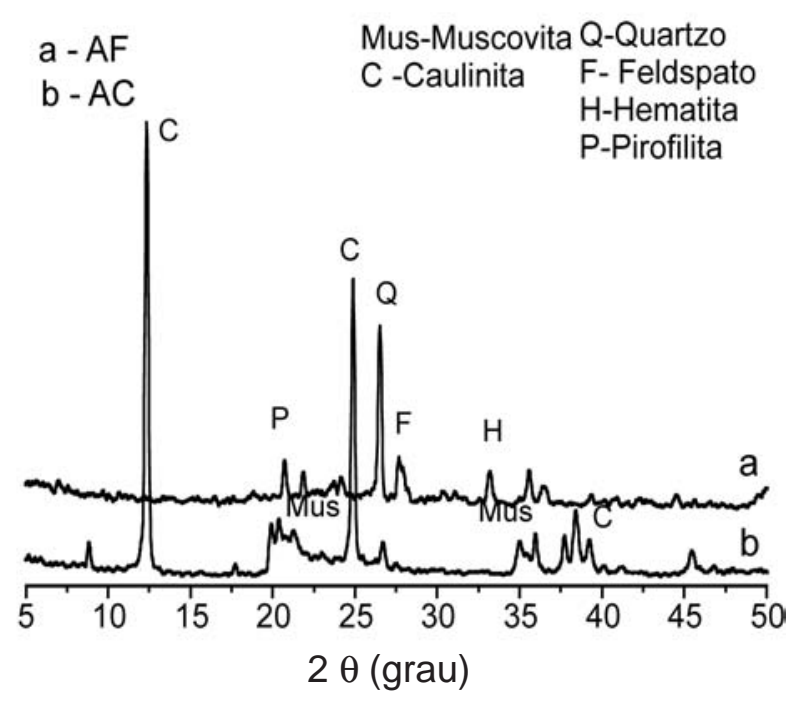

Figura 2: Difratogramas de raios $\mathrm{X}$ das matérias-primas naturais: (a) Matéria-prima AF; (b) Caulinita AC. Q-Quartzo, C-Caulinita, Mus-Muscovita, H-Hematita, F-Feldspatos, P-Pirofilita.

[Figure 2: X-ray diffraction patterns of the raw materials (a) raw material AF; (b) kaolin AC. Q-Quartz, C-kaolinite, Mus-Muscovite, H-Haematite, F-Feldspar, P-Phirophilite.]

de maneira que as amostras AF e AC apresentassem uma distribuição semelhante de tamanho de partículas (Tabela II).

As curvas termogravimétricas da AC e AF são apresentadas na Fig. 3. Constata-se a desidroxilação da AC em torno de $550{ }^{\circ} \mathrm{C}$ (Fig. 3a), com uma perda de água estrutural em torno de $13 \%$, que é próximo do teor presente na caulinita pura, $13,95 \%$. O baixo teor de argilominerais da AF (Fig. 3b) é confirmado pela perda de massa em torno de $7 \%$, na região de $500{ }^{\circ} \mathrm{C}$, também demonstrada pela perda ao fogo (Tabela I).

Observa-senaFig.4queoprocessodetermodecomposição da espuma polimérica inicia-se em torno de $220{ }^{\circ} \mathrm{C}$, com maior taxa em $250{ }^{\circ} \mathrm{C}$. Esta temperatura foi utilizada como patamar, para a eliminação da espuma polimérica após

Tabela I - Análise química da matéria-prima AF. [Table I - Chemical analysis of raw material AF.]

\begin{tabular}{cc}
\hline Analito & Resultados (\%) \\
\hline $\mathrm{SiO}_{2}$ & 61,40 \\
$\mathrm{Fe}_{2} \mathrm{O}_{3}$ & 4,09 \\
$\mathrm{Al}_{2} \mathrm{O}_{3}$ & 20,98 \\
$\mathrm{CaO}$ & Traços \\
$\mathrm{MgO}$ & Traços \\
$\mathrm{Na}_{2} \mathrm{O}$ & 1,80 \\
$\mathrm{~K}_{2} \mathrm{O}$ & 2,45 \\
Perda ao Fogo & 6,31 \\
Resíduos Insolúveis & 2,12 \\
\hline
\end{tabular}


Tabela II - Diâmetro médio de partículas das matériasprimas AF e AC.

[Table II - Average particle diameter of raw material AF and AC.]

\begin{tabular}{ccc}
\hline Diâmetro & $\mathrm{AF}(\mu \mathrm{m})$ & $\mathrm{AC}(\mu \mathrm{m})$ \\
\hline Diâmetro a 10\% & 1,27 & 1,07 \\
Diâmetro a 50\% & 7,07 & 5,86 \\
Diâmetro a 90\% & 30,00 & 24,44 \\
Diâmetro médio & 12,01 & 10,40 \\
\hline
\end{tabular}

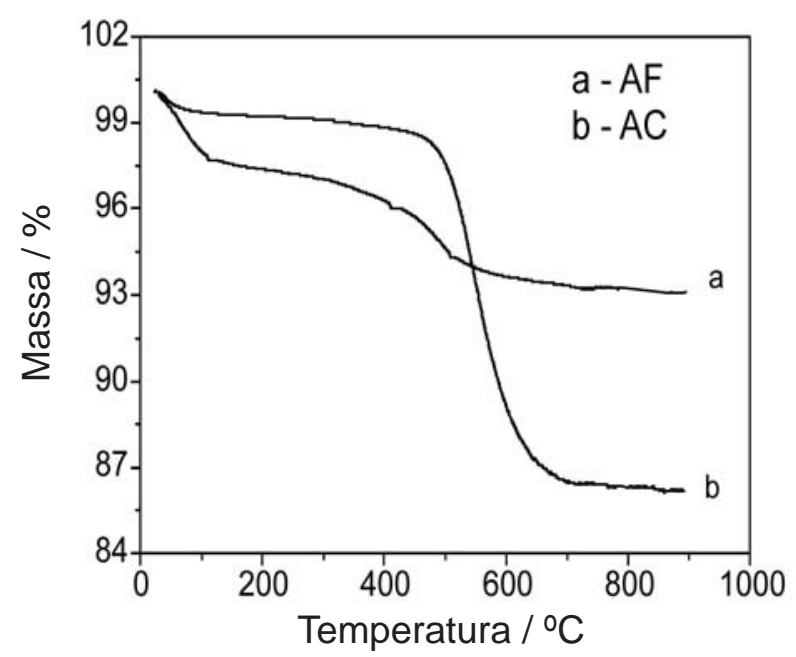

Figura 3: Curvas termogravimétricas das matérias-primas AF e AC. [Figure 3: Thermogravimetric curves of raw materials AF and AC.]

impregnação, evitando o colapso da estrutura cerâmica resultante.

A curva térmica diferencial da matéria-prima AC (Fig. 5a) mostra apenas as transições características da caulinita. Em torno de $570{ }^{\circ} \mathrm{C}$ há uma transição endotérmica correspondendo à perda de grupos hidroxila que cercam o $\mathrm{Al}$ na caulinita, levando à formação da metacaulinita. A 1034 ${ }^{\circ} \mathrm{C}$ verifica-se um pico exotérmico, devido à reorganização dos óxidos na rede estrutural da metacaulinita, dando lugar a uma forma semelhante ao espinélio $\gamma$-alumina, com composição $2 \mathrm{Al}_{2} \mathrm{O}_{3} \cdot 3 \mathrm{SiO}_{2}$, levando à subseqüente formação de pseudomulita. Em torno de $1200^{\circ} \mathrm{C}$ observa-se o início de outro pico exotérmico, provavelmente devido à formação de mulita. Verifica-se que as transições descritas ocorrem cerca de $30^{\circ} \mathrm{C}$ acima das temperaturas características das transições da caulinita, e este fato está relacionado com a alta taxa de aquecimento, que implica em erros na quantificação de eventos, mas mostra ser adequada na detecção de transições minerais e fusões com pequena troca de calor [19].

Verifica-se nas Figs. 5b a 5d, nas curvas de DTA da matéria-prima AF com 0 a $20 \%$ de AC, que há um início de processo endotérmico acima de $1100{ }^{\circ} \mathrm{C}$, que é variável com o teor de AC. Tal processo deve-se, provavelmente, à

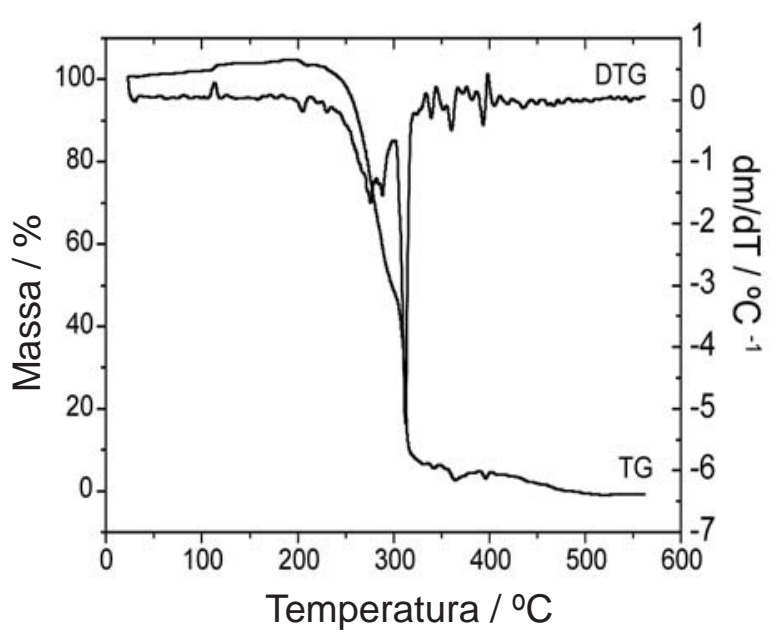

Figura 4: Curva TG e DTG da espuma de polimérica.

[Figure 4: Thermogravimetric curves (TG/DTG) of the polymeric foam.]

fusão dos feldspatos. De acordo com dados da literatura, os feldspatos de potássio e sódio fundem a 1150 e $1050{ }^{\circ} \mathrm{C}$, respectivamente [15]. O início de um pico endotérmico ocorre em torno de $1100^{\circ} \mathrm{C}$ para a amostra $\mathrm{AF}$, aumentando para aproximadamente $1120^{\circ} \mathrm{C}$ para a amostra com $10 \%$ de AC, e $1132{ }^{\circ} \mathrm{C}$ para a amostra com $20 \%$. Estes resultados definiram as temperaturas de sinterização das cerâmicas reticuladas acima de $1100{ }^{\circ} \mathrm{C}$.

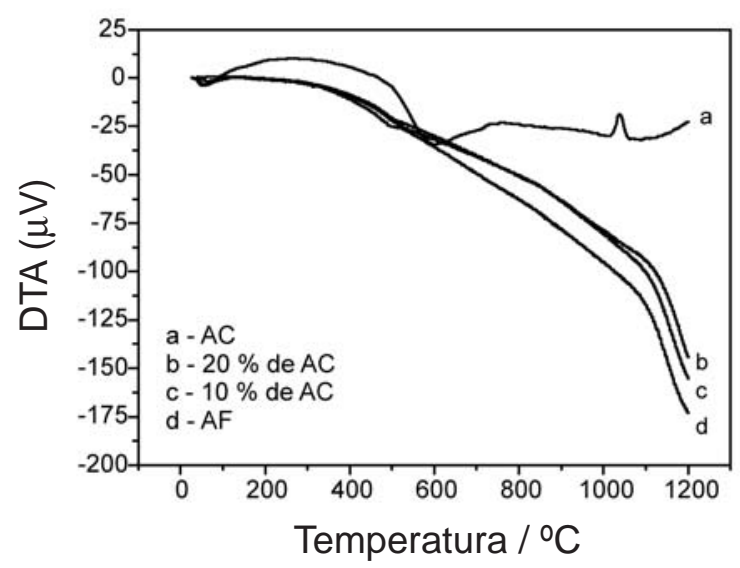

Figura 5: Curva térmica diferencial: (a) da caulinita (AC); das misturas com (b) $20 \% \mathrm{~m} / \mathrm{m}$ de AC; (c) $10 \% \mathrm{~m} / \mathrm{m}$ de AC e (d) da amostra AF.

[Figure 5: Differential thermal analysis (DTA) of: (a) raw material AC; mixtures with (b) $20 \% \mathrm{~m} / \mathrm{m}$ of AC; (c) $10 \% \mathrm{~m} / \mathrm{m}$ of AC and (d) raw material $A F$.]

\section{Caracterização das suspensões cerâmicas}

As curvas de viscosidade das suspensões preparadas com a amostra AF pura e com 10 e $20 \%$ de AC são apresentadas na Fig. 6. Durante os ensaios reológicos, foi observado um 


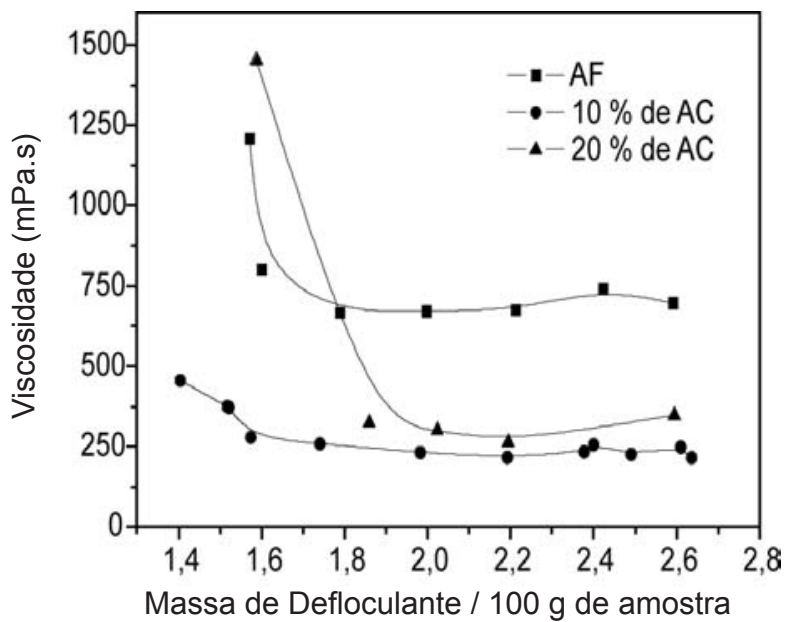

Figura 6: Viscosidades das suspensões contendo $70 \% \mathrm{~m} / \mathrm{m}$ das barbotinas com AF e das suspensões com 10 e $20 \%$ m/m de AC, em função da quantidade de PAA-Na.

[Figure 6: Viscosity of slurries containing $70 \% \mathrm{w} / \mathrm{w}$ of solids with raw material $A F$, with 10 and $20 \% \mathrm{w} / \mathrm{w}$ of $A C$, in relation to the amount of PAA-Na.]

(A)

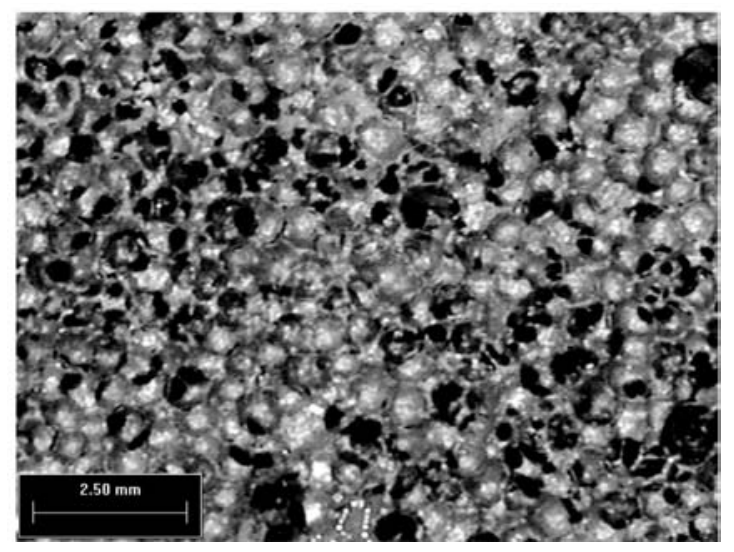

(C)

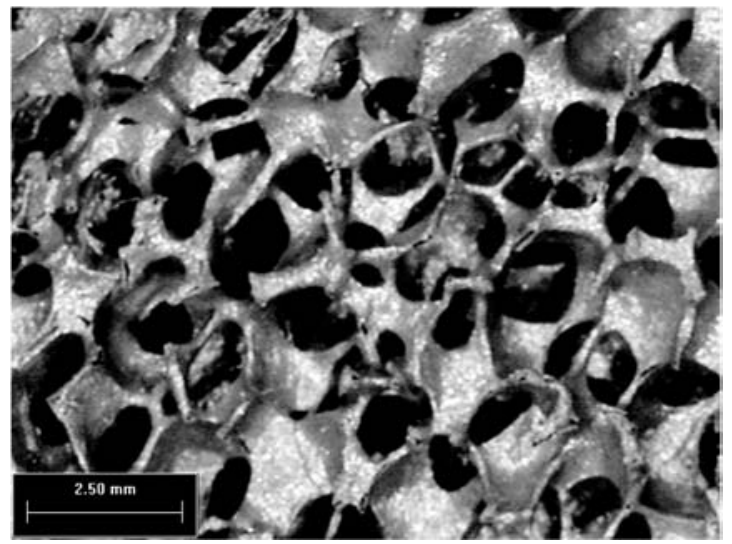

comportamento tixotrópico e pseudoplástico das suspensões cerâmicas, o que facilita a impregnação da espuma.

Verifica-se na Fig. 6 que, para um teor de 2,0\% de PAA$\mathrm{Na}$, após adição de AC, houve uma redução da viscosidade da suspensão contendo apenas AF, de 670 mPa.s para aproximadamente $250 \mathrm{mPa}$.s. Como AF e AC possuem praticamente a mesma distribuição de tamanho de partículas e a mesma densidade (AF: 2,62 g. $\mathrm{cm}^{-3}$ e AC:2,61 g.cm${ }^{3}$ ), acredita-se que a mudança se deve provavelmente à morfologia da partícula da amostra $\mathrm{AC}$ e a pouca deficiência de carga na estrutura [10].

Para a preparação das barbotinas utilizadas na impregnação da espuma polimérica, foram empregadas as suspensões com $70 \% \mathrm{~m} / \mathrm{m}$ de sólidos contendo AF pura e com 10 e $20 \%$ de AC contendo sempre $2,0 \% \mathrm{~m} / \mathrm{m}$ de PAA-Na.

Obtenção e caracterização das cerâmicas porosas reticuladas

As peças confeccionadas com a matéria-prima AF foram calcinadas somente na temperatura de $1100{ }^{\circ} \mathrm{C}$, pois acima desta ocorria o colapso das peças cerâmicas devido ao
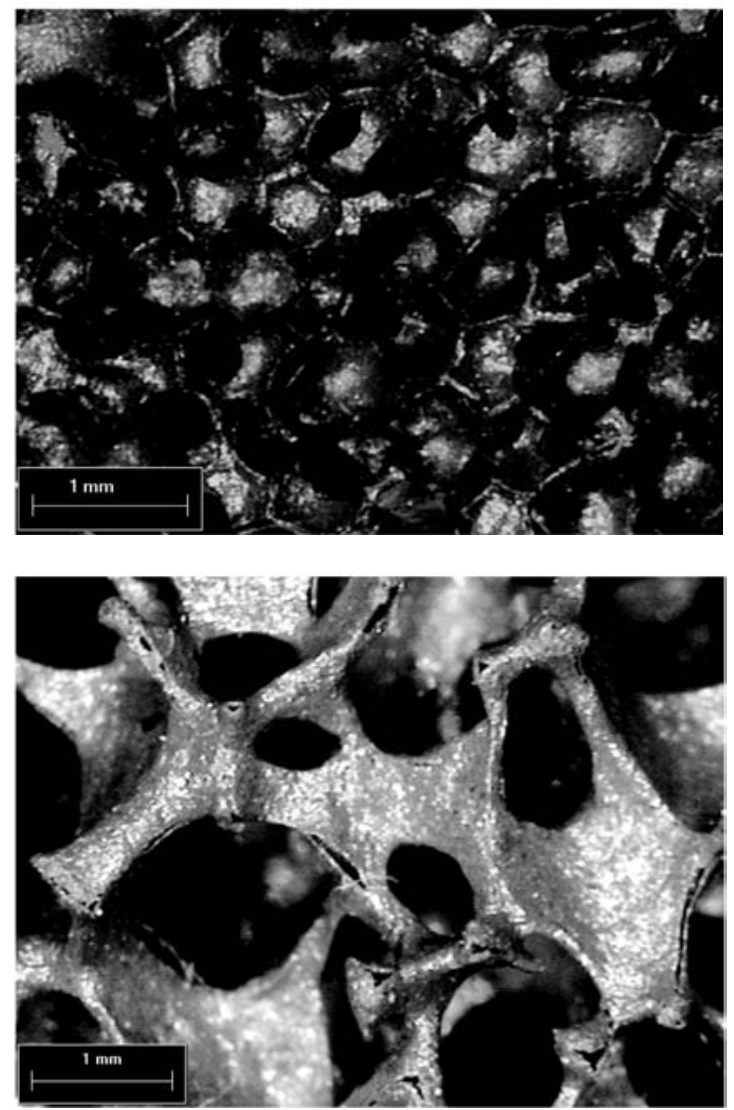

(D)

Figura 7: Micrografias obtidas por MEV das cerâmicas reticuladas, processadas com a matéria-prima AF, após sinterização a $1100{ }^{\circ} \mathrm{C}$. A, B: porosidade P (40 ppc) e C, D: porosidade M (10 ppc).

[Figure 7: SEM micrographs of reticulated ceramics prepared with the raw-material $\mathrm{AF}$, sintered at $1100{ }^{\circ} \mathrm{C}$. A, B: $\mathrm{P}$ porosity (40 ppc) and C, D: M porosity (10 ppc).] 
elevado teor de fundentes (Tabela I). As peças com 10 e 20\% $\mathrm{m} / \mathrm{m}$ de AC foram sinterizadas a $1200^{\circ} \mathrm{C}$.

As micrografias das cerâmicas reticuladas obtidas da mistura $\mathrm{AF}$, com a espuma polimérica $\mathrm{P}$ e $\mathrm{M}$, são apresentadas nas Figs. 7a a 7d. Pode-se observar a rede cerâmica característica das cerâmicas reticuladas, com uma boa impregnação da espuma polimérica. Na espuma com porosidade $\mathrm{M}$ (Fig. $7 \mathrm{~b}$ ) podem ser observados os poros provenientes da termodecomposição da espuma polimérica, que atuam como regiões de adsorção.

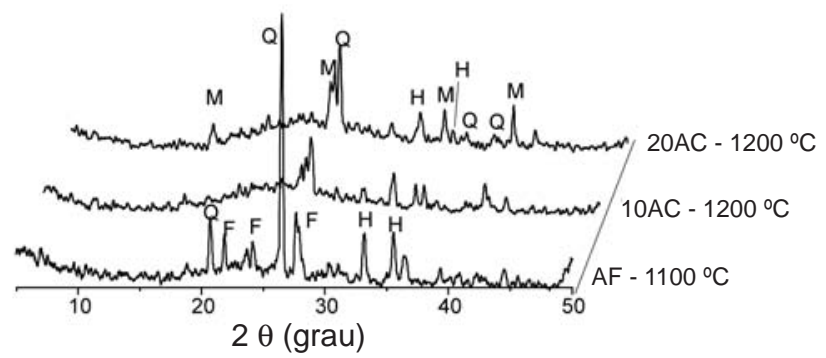

Figura 8: Difratogramas de raios X das massas usadas na obtenção das cerâmicas reticuladas, após tratamento térmico. M-mulita, Qquartzo, H-hematita, F-feldspatos.

[Figure 8: X-ray diffraction patterns of the material used in the processing of reticulated ceramics, after thermal treatment. QQuartz, M-Mullite, H-Haematite, F-Feldspar.]

No difratograma de raios $\mathrm{X}$ da peça cerâmica calcinada a $1100{ }^{\circ} \mathrm{C}$ (Fig. 8), contendo apenas AF, observa-se uma melhor definição dos picos do quartzo e feldspatos; os picos referentes aos feldspatos, provavelmente, são provenientes de fase que não fundiu ou reagiu com o quartzo, uma vez que a dissolução do quartzo ocorre em torno de $1200{ }^{\circ} \mathrm{C}$. Após adição da matéria-prima AC, com sinterização a 1200 ${ }^{\circ} \mathrm{C}$, há formação de mulita, com altura de pico proporcional ao teor de AC [15]. Há um alargamento dos picos de difração, indicando formação de fase vítrea, que dificulta a identificação de outros minerais presentes. Observa-se a redução no teor de quartzo, indicando sua dissolução, como também o desaparecimento dos feldspatos, em decorrência da fusão. Observa-se ainda picos de hematita, responsável pela coloração vermelha das peças.

Na Fig. 9 são apresentados os resultados de porosidade aparente, massa específica aparente e retração linear. A letra no eixo das abscissas corresponde à porosidade da espuma impregnada e o número que o acompanha indica o percentual de AC na mistura. Os resultados de retração linear (Fig. 9a) foram avaliados apenas para a espuma com porosidade 10 ppc (M), pois as amostras com porosidade $\mathrm{G}$ apresentaram uma grande dispersão dos dados, em função da abertura dos poros. As cerâmicas reticuladas obtidas somente com a matéria-prima $\mathrm{AF}$, calcinadas a $1100{ }^{\circ} \mathrm{C}$, apresentaram uma retração média em torno de 12,40\%, diminuindo para 9,33\% para a amostra 20AC. Este resultado deve-se a redução de fundente, associado à melhor trabalhabilidade da massa,
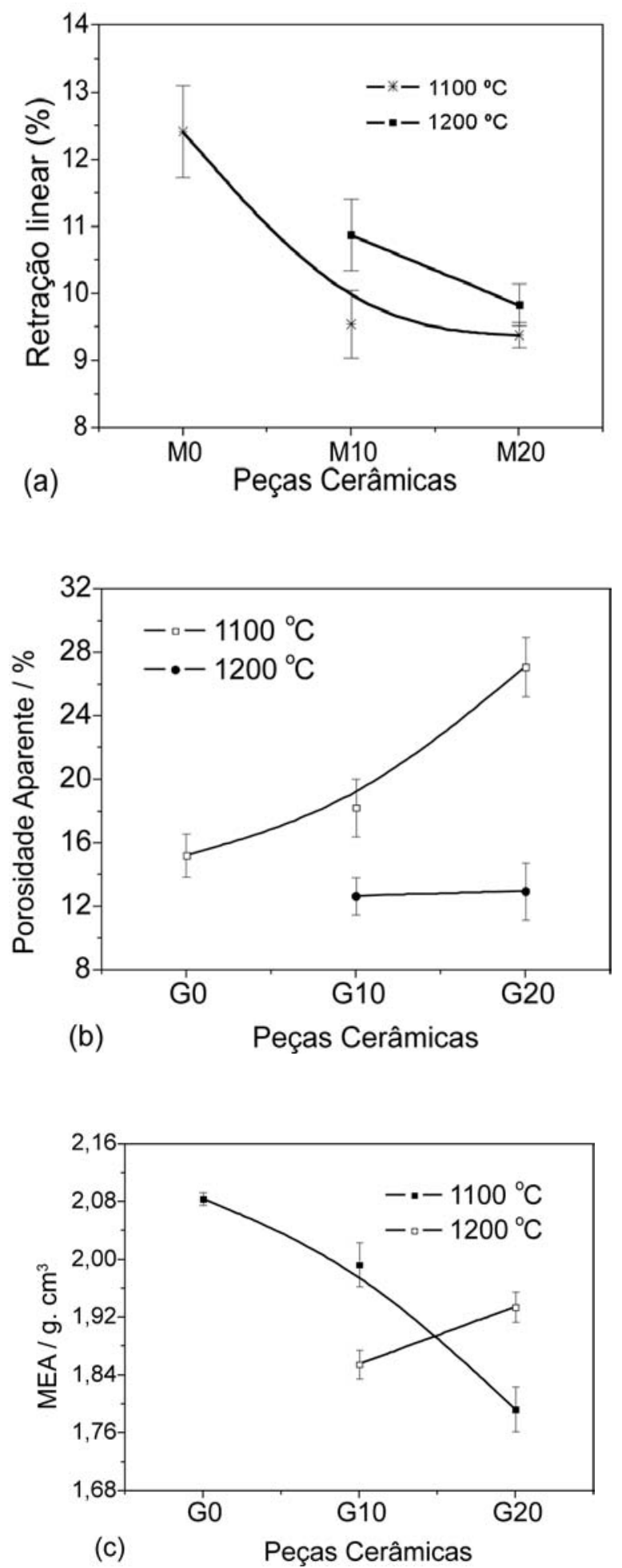

Figura 9: Propriedades das cerâmicas reticuladas, após sinterização: a) retração linear, b) porosidade aparente - PA, e c) massa específica aparente - MEA.

[Figure 9: Properties of the reticulated ceramics, after sintering: a) linear retraction, b) apparent porosity - PA, and c) apparent specific weight.] 
devido às mudanças nas propriedades reológicas, reduzindo a densidade a verde, após a adição de AC. A $1200{ }^{\circ} \mathrm{C}$, com o aumento do teor de AC, verifica-se uma retração cerca de 9,82\%, com uma peça composta basicamente por mulita e fase vítrea.

A porosidade aparente e massa específica aparente foram determinadas a partir das peças com porosidade 5 ppc (G), pois foi verificado que as peças com porosidade $\mathrm{M}$ e $\mathrm{P}$ retinham água, nos poros provenientes da espuma polimérica. A porosidade aparente (Fig. 9b), após calcinação a $1100{ }^{\circ} \mathrm{C}$, para as peças obtidas da matéria-prima AF foi de 15,16\%. Esta peça apresenta elevado teor de quartzo que provoca trincas devido ao processo de transição entre as fases do quartzo. Após adição de $\mathrm{AC}$ a $1100{ }^{\circ} \mathrm{C}$ não há sinterização da peça, observada pelo aumento da porosidade, que atinge o valor de 27,07\%. A $1200{ }^{\circ} \mathrm{C}$ observa-se uma redução acentuada da PA após adição de caulinita, com o valor em torno de 12,65\%, indicando uma boa sinterização. A peça confeccionada com a mistura AF apresentou uma MEA (Fig. 9c) em torno de 2,08 g.cm ${ }^{-3}$ a $1100{ }^{\circ} \mathrm{C}$, em função do elevado teor de fundentes, atingindo um valor de 1,79 g.cm ${ }^{-3}$ após adição de $20 \%$ de $\mathrm{AC}$, com sinterização a $1100{ }^{\circ} \mathrm{C}$, confirmando que a peça não se encontra sinterizada. A $1200{ }^{\circ} \mathrm{C}$ os valores da MEA encontram-se em torno de $1,91 \mathrm{~g} . \mathrm{cm}^{-3}$.

Para avaliação da resistência à compressão das cerâmicas reticuladas, foram realizados testes com as peças obtidas das misturas AF, calcinadas a $1100^{\circ} \mathrm{C}$, e da contendo $20 \%$ de AC calcinada a $1200^{\circ} \mathrm{C}$, obtendo valores de $1,5 \pm 0,3$ e $1,7 \pm 0,3$ MPa, respectivamente. O aumento da resistência mecânica da peça 20AC é provavelmente devido ao efeito da mulita e da melhor sinterização.

Das cerâmicas porosas reticuladas, escolheu-se a oriunda

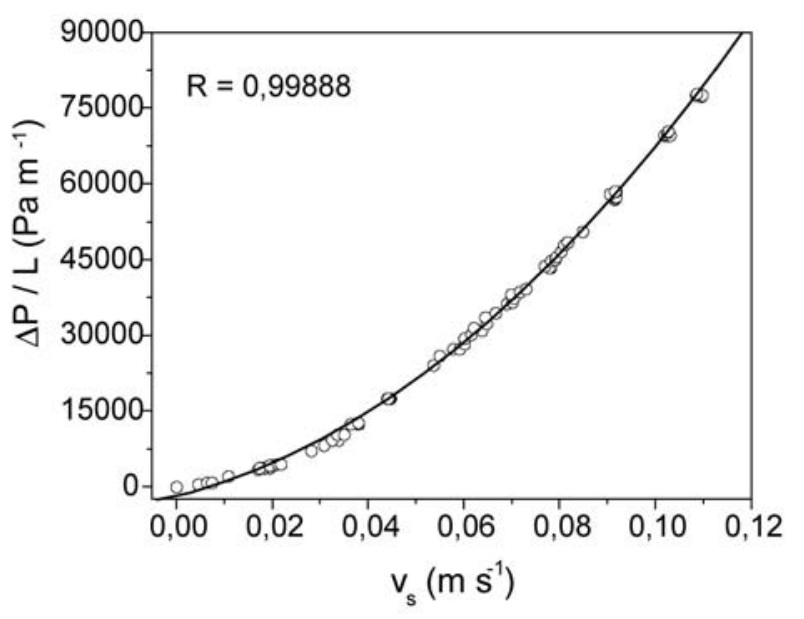

Figura 10: Determinação da permeabilidade da cerâmica reticulada, preparada com uma espuma polimérica de 10 ppc e barbotina contendo $20 \%$ de AC, sinterizada a $1200{ }^{\circ} \mathrm{C}$.

[Figure 10: Permeability determination for reticulated ceramic, processed using 10 ppc polymeric sponge, and a slurry containing $20 \%$ of AC, sintered at $1200^{\circ} \mathrm{C}$.] da espuma com 10 ppc, obtida a partir da amostra com 20AC, calcinada a $1200{ }^{\circ} \mathrm{C}$, para a determinação das constantes de permeabilidade. $\mathrm{O}$ gráfico da relação entre a perda de pressão pelo comprimento do leito $(\Delta \mathrm{P} / \mathrm{L})$ em função da velocidade do fluxo de água $\left(\mathrm{v}_{\mathrm{s}}\right)$ é observado na Fig. 10. Os valores das constantes de permeabilidade darciana $\left(\mathrm{k}_{1}\right)$, e o da constante de permeabilidade não darciana $\left(\mathrm{k}_{2}\right)$ foram, respectivamente, $3,58.10^{-9}( \pm 10,0 \%) \mathrm{m}^{2}$, e $2,15.10^{-4}( \pm 7,11$ \%) $\mathrm{m}$. Estes resultados indicam que as cerâmicas produzidas apresentam permeabilidade que permitem aplicá-las em sistemas em fluxo.

\section{CONCLUSÕES}

O emprego de matérias-primas naturais compostas por argilominerais, feldspatos e quartzo permite reduzir os custos de produção das cerâmicas reticuladas, uma vez que apresentam temperatura de sinterização em torno de 1200 ${ }^{\circ} \mathrm{C}$, que é uma faixa relativamente baixa.

A mistura de matérias-primas naturais facilitou o emprego do processo de impregnação em espuma polimérica, pois as suspensões argilosas apresentaram boa plasticidade com elevado teor de sólidos, com uma viscosidade variável entre 600 e $250 \mathrm{mPa}$.s, sendo tixotrópicas e pseudoplásticas, aderentes em espuma polimérica, e após secagem apresentam boa resistência mecânica a verde, tornando dispensável a utilização de outros aditivos, além do defloculante.

As peças confeccionadas a $1100{ }^{\circ} \mathrm{C}$ a partir da matériaprima pura, e a $1200^{\circ} \mathrm{C}$ após adição de caulinita, apresentaram resultados de massa específica aparente, porosidade aparente e absorção de água que indicaram sinterização, sem causar o colapso da estrutura macroporosa das cerâmicas reticuladas com porosidade 5, 10 e 40 ppc. A cerâmica reticulada com porosidade de $10 \mathrm{ppc}$ apresentou estrutura suficientemente rígida, com resistência mecânica superior a $1,70 \mathrm{MPa}$, com constante de permeabilidade darciana na ordem de 3,58.10 ${ }^{-9}$ $( \pm 10,0 \%) \mathrm{m}^{2}$, adequada para processos em fluxo.

\section{AGRADECIMENTOS}

Ao CNPq pelo suporte financeiro.

\section{REFERÊNCIAS}

[1] J. Adler, H. Heymer, G. Standke, Forum of Technology, DKG, 76, 9 (1999) 19.

[2] A. Shingo, U. S. Pat. 5.190 .897 (Mar 2, 1993).

[3] M. A. Alvin, Ind. Eng. Chem. Res., 35 (1996) 3384.

[4] J. T. Richardson, D. Remue, J. K. Hung, Appl. Catal. A: Gen. 250 (2003) 319

[5] F. S. Ortega, K. M. Rocha, M. Zait, V. C. Pandolfelli, Cerâmica 47, 304 (2001) 1999.

[6] P. Sepulveda, A. H. Bressiani, J. C. Bressiani, L. Meseguer, B. J. Konig, J. Biomed. Mat. Res. 62, 4 (2002) 587. 
[7] P. Sepulveda, J. G. P. Binner, J. Eur. Ceram. Soc. 19 (1999) 2059.

[8] K Schwartzwalder, V. Somers, U. S. Pat. 3.090.094 (May 21, 1963).

[9] J. Saggio-Woyansky, C. E. Scott, W. P. Minnear, Am. Ceram. Soc. Bull. 71, 11 (1992) 1674.

[10] H. H. Murray, Appl. Clay Sci. 17 (2002) 207.

[11] W. D. Kingery, H. K. Bowen, D. R. Uhlmann, Introduction to Ceramics, $2^{\text {nd }}$ Ed., John Wiley \& Sons, Inc.,
New York (1976).

[12] C. O. Ingamells, Anal. Chem. 38, 9 (1966) 1228.

[13] M. C. Mayoral, M. T. Izquierdo, J. M. Andrés, B. Rubio, Thermochim. Acta 373 (2001) 173.

[14] M. D. M. Innocentini, P. Sepulveda, V. R. Salvini, V. C. Pandolfelli, J. Am. Ceram. Soc. 81, 12 (1998) 3349.

[15] W. E. Lee, Y. Iqbal, J. Eur. Ceram. Soc. 21 (2001) 2583.

(Rec. 13/09/2005, Ac.11/11/2005) 